\title{
Oficinas com Meninas em uma Escola Aberta: Espaço de Diálogo, Reflexão e Reconhecimento da Singularidade
}

\author{
Sabrina Dal Ongaro Savegnago ${ }^{1}$ \\ Programa de Pós Graduação em Psicologia da Universidade Federal do Rio de Janeiro, \\ Rio de Janeiro, RJ, Brasil \\ Suane Pastoriza Faraj \\ Entidade Palotina de Educação e Cultura, Santa Maria, RS, Brasil \\ Universidade Federal de Santa Maria, Santa Maria, RS, Brasil \\ Dorian Mônica Arpini \\ Aline Cardoso Siqueira \\ Departamento de Psicologia da Universidade Federal de Santa Maria, \\ Santa Maria, RS, Brasil \\ Programa de Pós-Graduação em Psicologia da Universidade Federal de Santa Maria,
}

Santa Maria, RS, Brasil

\section{Resumo}

Este trabalho apresenta um relato de experiência de ações realizadas por meio do Projeto de Extensão intitulado "Oficinas com adolescentes em uma escola aberta: Discutindo sobre violência, sexualidade, drogas e projeto de vida". O projeto foi desenvolvido por uma equipe composta por professoras-orientadoras psicólogas, mestrandas e acadêmicas do Curso de Psicologia. As oficinas foram realizadas com meninas de 12 a 17 anos em uma escola localizada em uma cidade do interior do Rio Grande do Sul. Trata-se de uma instituição governamental que funciona na modalidade de escola aberta, atendendo alunos de 10 a 18 anos. Estes alunos tiveram suas trajetórias de vida marcadas por muitas fragilidades, como uso de drogas e exposição à violência. Assim, o desenvolvimento das oficinas teve como intuito oferecer espaços de diálogo e reflexão, no sentido de proporcionar momentos de elaboração de experiências negativas, além de possibilitar a construção de projetos de vida. Nas oficinas com as adolescentes, que ocorreram quinzenalmente, percebeu-se que determinados assuntos fizeram-se presentes de forma significativa. Dentre eles, destacam-se as relações familiares, violência, sexualidade, em especial a questão a gravidez na adolescência e projetos de vida. Estes tópicos serão foco de reflexão ao longo do artigo. A partir da avaliação ao final da ação, pode-se constatar que a oficina constituiu-se em um momento reflexivo sobre o presente e os planos para o futuro.

Palavras-chave: Oficinas, escola aberta, adolescentes.

\section{Workshops with Girls in an Open School: Space for Dialogue, Reflection and Recognition of Singularity}

\footnotetext{
Abstract

This study presents an experience report of actions accomplished through an extension Project entitled "Workshops with adolescents in an open school: Discussing about violence, sexuality, drugs and life

Endereço para correspondência: Praia de Botafogo, 356, Apto. 329, Bairro Botafogo, Rio de Janeiro, RJ, Brasil 22250-040. E-mail: sabrinadsavegnago@gmail.com, suanef@yahoo.com.br, monica.arpini@gmail.com e alinecsiq@gmail.com
} 
projects". The project was developed by a team of teachers - psychology advisors, psychology masters students and undergraduate students. The workshops were accomplished with 12-17 years old girls, in a school located in the interior of Rio Grande do Sul. It is a governmental institution that works as an open school, where students from 10 to 18 years old develop activities. Those students had their life trajectories characterized by several fragilities, such as use of drugs and exposure to violence. Therefore, the development of the workshops aimed to offer spaces of dialogue and reflection, in the sense of providing moments of working through negative experiences, besides enabling the construction of projects of life. In the fortnightly workshops with the adolescents, several significant subjects arose. Among them, family relationships, violence, sexuality, and especially pregnancy in adolescence and projects of life were highlighted. Such topics will be focus of discussion throughout the article. The evaluation of the activities evidences that the workshops were a moment of reflection about the present and plans for the future.

Keywords: Workshops, open school, adolescents.

\section{Talleres con Niñas en una Escuela Abierta: Espacio para el Diálogo, la Reflexión y el Reconocimiento de la Singularidad}

\section{Resumen}

Este trabajo presenta un relato de experiencia de las acciones realizadas a través del Proyecto de Extensión titulado "Talleres con adolescentes en una escuela abierta: discutiendo sobre la violencia, la sexualidad, las drogas y el proyecto de vida". El proyecto fue desarrollado por un equipo de profesoraspsicólogas como orientadoras, alumnas del master y académicas del Curso de Psicología. Los talleres se llevaron a cabo con niñas de 12-17 años en una escuela ubicada en una ciudad del interior del Rio Grande do Sul. Se trata de una institución gubernamental que trabaja en forma de escuela abierta, que asiste a estudiantes de 10 a 18 años. Estos alumnos tuvieron sus trayectorias de vida marcadas por muchas debilidades, como el uso de drogas y la exposición a la violencia. Por lo tanto, el objetivo del desarrollo de los talleres fue proporcionar espacios para el diálogo y la reflexión con el fin de proporcionar momentos de elaboración de experiencias negativas, además de posibilitar la construcción de proyectos de vida. En los talleres, con los adolescentes, que ocurrieron a cada dos semanas, se observó que algunos temas estaban presentes de manera significativa. Entre ellos, se destacan las relaciones familiares, la violencia, la sexualidad, en especial el tema del embarazo adolescente y proyectos de vida. Estos asuntos serán el objeto de reflexión lo largo del artículo. Desde la evaluación hasta el final de la acción, se pudo constatar que el taller consistió en un momento reflexivo sobre el presente y los planes para el futuro.

Palabras clave: Talleres, escuela abierta, adolescentes.

Existem milhares de crianças e adolescentes em situação de vulnerabilidade social no Brasil. São meninos e meninas que foram expostos a inúmeros fatores ao longo do seu desenvolvimento, e que, ao invés de serem protegidos e acolhidos, se veem afastados da sociedade. Suas famílias de origem estão tão fragilizadas que não conseguem mais acolhê-los, sendo muitas vezes consideradas, tanto por professores, profissionais da saúde, dirigentes de instituições de acolhimento, quanto pela sociedade em geral, incapazes de cuidar, educar e criar seus filhos (Arpini \& Quintana, 2009; Rizzini, Rizzini, Naiff, \& Baptista, 2006; M. L. Silva, Polli, Sobrosa, Arpini, \& Dias, 2012; Yunes \& Szymanski, 2003). As escolas regulares parecem não ter espaço para estes jovens e, dessa forma, a proteção ficaria a cargo das instituições de assistência à infância e juventude em situação de vulnerabilidade, como as escolas abertas.

O conceito de vulnerabilidade adotado é o proposto por Meyer, Mello, Valadão e Ayres 
(2006), para os quais as situações de vulnerabilidade são constituídas por três componentes que estão interligados: o individual, o social, o programático ou institucional. Em relação aos componentes de vulnerabilidade individual, estes são de ordem cognitiva e comportamental. A vulnerabilidade está relacionada a algum agravo, em especial, aos comportamentos que possibilitam que as pessoas contraiam doenças. $\mathrm{O}$ componente social abarca tanto o acesso às informações quanto as possibilidades destas provocarem mudanças na vida diárias dos sujeitos, estando relacionada ao acesso à saúde, educação, instituições sociais, entre outros. Já o componente institucional ou programático atrela os componentes individual e social, envolvendo assim, "o grau e a qualidades de compromisso, recursos, gerência e monitoramento de programas nacionais, regionais ou locais de prevenção e cuidado" (p. 1340).

As instituições de ensino denominadas "escolas abertas" foram criadas em 1987 com a proposta pedagógica de construir uma escola pública e democrática para crianças e adolescentes menos favorecidos da sociedade e que se encontram em situação vulnerabilidade. No interior do Rio Grande do Sul, apenas em 1996, crianças e adolescentes com defasagem escolar e em situação de rua, com idades entre 10 e 18 anos e com mais de dois anos de repetência e/ou evasão das séries iniciais do Ensino Fundamental, começaram a ser acolhidos nestas instituições (Ramos, 2004). As escolas abertas se caracterizam pela oferta de um atendimento educacional específico e têm como objetivo a inserção da criança e do adolescente na sociedade (Vargas, Buss, \& Bayer, 2008). Além disso, estas instituições visam, por meio de uma estrutura flexível, proporcionar um atendimento mais individualizado aos seus alunos, considerando o contexto no qual os mesmos estão inseridos.

Muitas vezes, os meninos e meninas que se encontram matriculados em escolas abertas já fizeram uso de drogas e foram expostos à violência em suas trajetórias de vida. Em decorrência disso, faz-se necessário oportunizar espaços a esses adolescentes, nos quais possam resgatar suas potencialidades e superar as expectativas negativas que carregam consigo (Arpini, 2003).

Neste sentido, o desenvolvimento de oficinas psicossociais e lúdicas junto aos estudantes de uma escola aberta propôs construir um espaço de diálogo e reflexão, visto que pode proporcionar momentos de elaboração e superação de experiências negativas, como também possibilitar a reflexão sobre projetos de vida. Desse modo, este trabalho tem como objetivo retratar algumas ações que foram desenvolvidas por meio do Projeto de Extensão intitulado "Oficinas com adolescentes em uma escola aberta: Discutindo sobre violência, sexualidade, drogas e projeto de vida". Além disso, uma reflexão teórica acerca de alguns aspectos significativos que se fizeram presentes ao longo das oficinas será realizada.

\section{Oficinas com Adolescentes: Um Espaço de Escuta e Reflexão}

As oficinas com adolescentes foram realizadas em uma escola localizada em uma cidade do interior do Rio Grande do Sul. Trata-se de uma instituição governamental que funciona na modalidade de escola aberta, atendendo alunos de 10 a 18 anos. As principais fontes de encaminhamento dos alunos são os conselhos tutelares, as instituições de acolhimento, o Centro de Atendimento Sócio Educativo (CASE), além de outras escolas da rede pública. A escola aberta funciona no sistema de etapas, sendo que cada etapa corresponde a duas séries, totalizando assim um ciclo de quatro etapas. A instituição atende uma média de 18 a 20 alunos por dia. Em decorrência de suas histórias de vida, marcadas por muitas fragilidades e da proposta mais flexível da escola, identifica-se que há uma grande circulação dos alunos, muitas faltas e alguns apresentam pouca adesão à instituição, sendo este um dos aspectos que tem preocupado a equipe das oficinas. As aulas acontecem pela manhã, enquanto que à tarde ocorrem oficinas pedagógicas de padaria, papel reciclado, matemática na cozinha, teatro, cabeleireiro e informática.

O projeto das oficinas teve o intuito de responder à demanda identificada na escola aberta 
a partir de duas pesquisas realizadas pela equipe vinculada ao Departamento de Psicologia, de uma universidade do interior do Rio Grande do Sul. Uma das pesquisas teve como foco os diálogos sobre sexualidade no âmbito familiar, e foi realizada com meninas. Já o segundo estudo abordou o tema da violência sexual contra crianças e adolescentes e teve como participantes meninos da instituição. Ambas as pesquisas utilizaram a técnica de grupos focais. Assim, a partir destes estudos, identificou-se uma necessidade por parte da escola e dos próprios adolescentes para que fossem realizados grupos para tratar de temas como sexualidade, família, drogas, violência, dentre outros. Destaca-se que a aproximação da universidade com a sociedade é um dos pilares da ação extensionista e, nesse sentido, este projeto pretendeu fortalecer o vínculo entre a universidade e a comunidade por meio das ações que foram realizadas.

A ação foi desenvolvida por uma equipe de oito pessoas, composta por acadêmicas do Curso de Psicologia e mestrandas do Programa de Pós Graduação em Psicologia da referida instituição de ensino, sob a orientação de docentes do Departamento de Psicologia. No ano de 2012, foram realizados grupos com adolescentes, divididos por sexo e faixa etária. Inicialmente, ocorreu a inserção no campo e a observação da rotina dos jovens matriculados na escola aberta. Após esse período de aproximação, os adolescentes foram divididos em três oficinas: (a) para as meninas; (b) para os meninos de 12 a 14 anos; e (c) para os meninos de 15 a 18 anos incompletos. Ressalta-se que neste artigo serão abordadas questões relacionadas apenas às oficinas realizadas com as meninas. Estas foram desenvolvidas quinzenalmente, com dias previamente determinados e com duração de aproximadamente 1 hora e 30 minutos, no período de abril a dezembro de 2012 nas dependências da escola, coordenadas por duas psicólogas, mestrandas em Psicologia. Além disso, a ação extensionista foi supervisionada semanalmente, de forma grupal, visando à troca de ideias, à avaliação das oficinas realizadas e ao planejamento dos encontros subsequentes.

Dentre as ferramentas de apoio das oficinas, como forma de possibilitar a expressão dos sen- timentos e percepções dos adolescentes sobre os temas em discussão, foram utilizados materiais lúdicos e audiovisuais, como vídeos e filmes. As coordenadoras preparavam com antecedência propostas de atividades para serem realizadas durante as oficinas. Dentre elas, pode-se citar a dinâmica "Quem sou eu?", que teve como objetivo favorecer a inclusão do grupo, permitir maior conhecimento entre seus integrantes e apresentação de todos, e a atividade "Frases para completar", em que se abordaram questões como o significado de família, o significado de ser mãe, de ser pai e ser filho, o que é ser adolescente, como as adolescentes imaginavam que seria ser adulto, dentre outras. Além disso, uma oficina foi destinada à construção de um cartaz pelas meninas, no qual foram escritas combinações para o funcionamento dos encontros.

Participaram inicialmente da ação oito meninas, com idades entre 12 e 17 anos e com histórico de violação de direitos. No decorrer do ano, permaneceram apenas duas adolescentes devido a alguns fatores, dentre eles, evasão escolar, já apontada anteriormente, gravidez e reintegração familiar de meninas que estavam em acolhimento. Após a realização dos encontros, anotações em um diário de campo eram realizadas minunciosamente pelas duas coordenadoras da oficina, que foram utilizadas para esse relato de experiência. Durante a realização das oficinas, determinados assuntos fizeram-se presentes de forma significativa. Dentre eles, destacam-se as relações familiares, violência, sexualidade, em especial a questão a gravidez na adolescência e projetos de vida. Estes tópicos serão foco de análise e discussão. Ao longo do artigo, as participantes das oficinas serão mencionadas a partir de nomes fictícios, a fim de que suas identidades sejam preservadas.

\section{Ambiente Familiar: Espaço de Proteção ou Violação de Direitos?}

A família de hoje é fruto de uma concepção histórico-social (Ariès, 1981) e encontra-se em constante mudança por fazer parte dos dinamismos próprios das relações sociais. Apesar desse cenário de transformações e da variedade de for- 
mas que assume ao longo do tempo, a família mantém como uma de suas principais funções cuidar de seus filhos, constituindo-se num espaço privilegiado para o pleno desenvolvimento da criança (M. L. Silva et al., 2012; Winnicott, 1986/2005).

Para o adolescente, a família representa um eixo de referências simbólicas, sendo espaço de afetividade e, deste modo, lugar também de conflitos. É o lugar onde ocorre a aquisição da linguagem, sendo possível, por meio dessa, organizar, elaborar e dar sentido às experiências vividas. Assim, a família é o filtro a partir do qual se começa a olhar e dar significado ao mundo (Arpini, 2003; Sarti, 2004).

A família também é um sistema que tem a função de proteção tanto física quanto emocional do indivíduo, devido ao desamparo próprio da espécie humana (Groeninga, 2003). As adolescentes participantes das oficinas falaram da família como assumindo um papel significativo e fundamental em suas vidas, como pode ser identificado nas seguintes afirmações: "Para mim é tudo, eu sem família não sou nada, graças a Deus eu tenho. Minha família é muito especial para mim. Ter uma família para brincar e rir comigo..." (Fernanda, 15 anos). "Muito importante para mim, apesar de tudo" (Camila, 16 anos).

Considerando-se a história de Camila, narrada nas oficinas, poderia se pensar que, o "apesar de tudo" representa algumas de suas vivências de agressão física e psicológica no âmbito familiar. Kehl (2008) aponta a agressividade como o afeto mais nocivo da vida familiar. É comum que este afeto, que geralmente é controlado no meio social, seja liberado no espaço privado da família. Desse modo, agressões físicas e verbais, diretas ou indiretas, feitas por familiares, por vezes em nome do amor e da moral, podem causar marcas profundas. Ao se relacionar família com afetos, pode-se inicialmente ter a ideia de que esta é sempre fonte de compreensão, carinho e proteção. No entanto, vive-se em dívida com este ideal de família perfeita "com os 'bons' afetos todos no lugar certo" (p. 57).

Para Bia (12 anos), participante de todas as oficinas realizadas, família é "todos juntos, sem brigas e discussões em casa e na rua". É notório que este seria o ideal de família para Bia, pois a sua não tinha estas características, sendo marcada por quebras de vínculos e por situações de violência. Isso pode ser verificado na seguinte afirmação da adolescente: "Minha infância era um pouco dificil, porque meu pai batia na minha mãe na minha frente e batia em mim e nos meus irmãos". Dessa forma, pode-se identificar que o sistema familiar para as meninas participantes não estava, muitas vezes, vinculado à capacidade do cuidado, da oferta de afeto e do suprimento das necessidades. O espaço familiar representava, em diversas situações, um cenário de violação de direitos. Nesse sentido, considerar a pluralidade de possibilidades de experiências e organizações familiares vividas pelas adolescentes, contrapondo a uma concepção universal de família é importante. Destaca-se a necessidade de se flexibilizar o olhar sobre as diferentes formas de organizações familiares (famílias monoparentais, ampliadas, reconstituídas, adotivas, homoafetivas, entre outras). Tal olhar evita preconceitos e busca compreender os efeitos destas múltiplas formas de relações familiares, inclusive aquelas nas quais o exercício das funções materna e paterna não se mantém, ou são responsabilidade de um único membro, geralmente a mãe, ou ainda ficam a cargo de outros membros da família extensa, fragilizando a proteção e o amparo desejado e necessário para os filhos (Arpini \& Quintana, 2009; Neder, 1994). No entanto, apesar das experiências familiares de violência relatadas pelas participantes, elas continuavam valorizando e dando sentido à experiência familiar. Neste sentido, poderia-se pensar que, além de apresentarem em seus discursos um modelo de família almejado por elas, as adolescentes estariam reproduzindo um discurso ainda esperado de família ideal e perfeita, aquela na qual poderiam sentir-se seguras e protegidas. Segundo Polli e Arpini (2012), em estudo realizado com crianças pobres no Brasil, pode-se perceber que a família ideal retratada por elas é aquela em que os pais gostam e tratam bem dos filhos, todos estão juntos/unidos, são felizes e não brigam.

Dentre as formas de violação de direitos, a que se destacou no relato das meninas no pe- 
ríodo da realização das oficinas foi a violência intrafamiliar sofrida pelas mesmas. Diante da temática, pode-se afirmar que vem ocorrendo uma tomada de consciência acerca da dimensão e das implicações da violência infanto-juvenil (Eliachef, 2007). Esta pode ser compreendida quando existe um laço familiar, biológico ou não, entre a criança ou adolescente e o adulto agressor, ou ainda, quando há uma relação de responsabilidade entre a vítima e o agressor (Conselho Federal de Psicologia [CFP], 2009; Ippolito, 2004). É importante destacar que a negação da violência intrafamiliar contribuiu para levar muitas crianças à morte, já que, diante do desconhecimento e da falta de comprometimento da família e da sociedade, grande parte delas não teve chance de ser protegida. Nos últimos anos, ocorreram mudanças significativas na forma de se encarar a questão dos maus tratos contra crianças e adolescentes e o lugar ocupado pela criança na família (Eliachef, 2007). No entanto, ainda há altos índices de violência contra a população infanto-juvenil. O estudo realizado por Assis, Avanci, Pesce, Pies e Gomes (2012), referente à notificação de violência no Brasil, evidenciou que a violência contra crianças acontece de forma preponderante na residência das mesmas. Apontou que os dois tipos de violência de maior incidência em crianças menores de um ano de idade são a negligência/abandono (63,2\% das notificações) e a violência física (28\%). Entretanto, em relação às crianças de um a nove anos de idade, as violências mais notificadas foram a sexual $(41,7 \%$ das notificações) e a física (32,5\%). Outros estudos também apontam que a violência contra crianças e adolescentes ocorre com mais frequência dentro da família (Arpini, Siqueira, \& Savegnago, 2012; Cecconello, Antoni, \& Koller, 2003; Habigzang, Koller, Azevedo, \& Machado, 2005).

Nas oficinas, várias formas de violência no ambiente familiar foram relatadas pelas adolescentes, dentre elas, violência física, psicológica, sexual e negligência. Destaca-se que as notificações e os procedimentos necessários à proteção em casos de violência já haviam sido realizados pela instituição escolar. As meninas participantes eram acompanhadas pelo Conselho Tutelar do município, na época da realização das ofici- nas. Entretanto, pôde-se perceber, a partir dos relatos, o medo de notificar e, assim, perder a família. Este aspecto ficou evidente na fala de Camila (16 anos), referindo-se à violência física sofrida pelo padrasto e pela mãe e à tentativa de abuso sexual por parte do padrasto: "Eu tinha medo que o conselho tutelar me tirasse de casa, me colocasse num abrigo e eu nunca mais pudesse ver meus irmãos". Neste caso, o Conselho Tutelar não é visto como um órgão protetor, mas como uma instituição que vai tirar a vítima da família, separá-la de seus irmãos. É importante salientar que o Conselho Tutelar atua na esfera municipal e é encarregado de zelar pelo cumprimento dos direitos da criança e do adolescente. Ele atua em duas frentes de ação: uma preventiva e outra remediativa. À primeira cabe a fiscalização de entidades, a mobilização da comunidade ao exercício de direitos assegurados a todo cidadão. A segunda se refere à ação diante da violação consumada, defendendo e garantindo a proteção especial preconizada pelo Estatuto da Criança e do Adolescente (Conselho Estadual dos Direitos da Criança e do Adolescente [CEDICA], 1999).

Neste sentido, parece ser importante refletir sobre o temor das adolescentes com relação à ação do Conselho Tutelar, aspecto que pode ser atribuído à falta de conhecimento a respeito do funcionamento do Conselho Tutelar, mas também a outros aspectos vivenciados, nos quais a experiência e a trajetória com conselheiros tutelares não foi percebida como protetiva, implicando mais perdas e retaliações do que ganhos (afetivos). Esse é sem dúvida um aspecto de extrema relevância, na medida em que os conselheiros tutelares têm a função de mediação dos conflitos e para tal precisariam estabelecer uma relação de confiança com aqueles que deles passam a depender na expectativa de sair da situação de violência em que se encontram. Assim, tal relação com o Conselho Tutelar pode ter sido um atravessador que as impediu de revelar as violências sofridas e, consequentemente, que estas fossem interrompidas.

Outro aspecto identificado nas oficinas ofertadas às adolescentes refere-se ao espaço que o adulto deveria, mas não está ocupando na sociedade, o que talvez possa estar contribuindo para 
a falta de proteção dos direitos das crianças e dos adolescentes. Destaca-se que o Estatuto da Criança e do Adolescente (Lei $\left.\mathrm{n}^{\circ} 8.069,1990\right)$ estabelece o dever de "todos", família, sociedade e poder público de segurar os direitos da população infanto-juvenil e colocá-los a salvo de todas as formas de violência.

Nas últimas décadas, a adolescência vem ocupando um espaço privilegiado ganhando um prestígio, no sentido que há um desejo de permanecer jovem e uma tendência de prolongamento dessa fase. Hoje, passa-se de uma juventude prolongada direto para a velhice, ficando vazio o espaço que deveria ser preenchido pelo adulto (Kehl, 2004, 2008). Notou-se este aspecto na narrativa de Fernanda (15 anos), quando esta afirmou que a mãe passa o dia jogando vídeo game, não se mostrando disponível para conversar com a filha, quando esta lhe solicita. Nesse caso, poderia-se pensar que esta mãe não está ocupando o lugar de adulto que lhe caberia, levando ao desamparo desta adolescente que, não tendo a atenção da mãe, busca um irmão mais velho, no qual encontra a abertura e a atenção que necessita para conversar sobre as questões que lhe angustiam.

Assim, percebe-se também o papel significativo que os irmãos podem assumir na vida de um adolescente. Nas famílias contemporâneas, nota-se que há uma tendência ao aparecimento de novas formas de alianças, entre elas a fraterna (Pereira \& Arpini, 2012). Por vezes, as ligações entre irmãos são mais sólidas e estáveis do que as alianças com os adultos. Isto se observa com frequência em famílias nas quais as relações dos adultos se rompem e recompõe várias vezes no decorrer da vida das crianças e adolescentes. Nestas situações, as relações horizontais apresentam-se como referências consistentes e como fontes de afeto e cumplicidade. Desse modo, a função fraterna pode atuar como complementar a função paterna no que se refere à constituição do sujeito (Kehl, 2003). Pode-se ilustrar essa afirmação através da postura de uma das meninas, que relatou ter deixado a mãe e os irmãos na capital para morar com a irmã, o cunhado e o sobrinho no interior. Essa mudança de residência possibilitou-a encontrar referência, assim como romper com a violência intrafamiliar a qual era exposta desde a mais tenra infância. Esta mesma menina, em uma das oficinas escreveu que o mais importante na sua vida eram seus irmãos. Diante disso, destaca-se que nesta fase do desenvolvimento é fundamental o estabelecimento de relações de confiança, amizade e cumplicidade.

\section{A Vivência da Adolescência}

O sentido da adolescência e a forma como esta é vivenciada pelas meninas estiveram entre os temas abordados nas oficinas. Bia (12 anos), durante a realização de uma atividade, descreveu o que é ser adolescente por meio da seguinte frase "Ser adolescente é ficar quieta e sem vontade de brincar e de falar. É ficar enjoada e triste. É ser mais ou menos legal com as pessoas e ficar mais comportada". A adolescência é considerada uma "época especialmente difícil da vida", sendo mais difícil quando se adiciona a dependência de álcool, desemprego, violência doméstica e a rejeição no ambiente familiar e fora dele. Ou seja, na comunidade e na escola que, muitas vezes "não encanta, não atrai, não seduz o imaginário jovem e não valoriza seus alunos" (Soares, 2004, p. 138).

Dentre os diversos assuntos que envolvem as vivências dos adolescentes, destacaram-se nas oficinas aqueles relacionados à sexualidade, como os relacionamentos afetivos, a "perda" da virgindade, a importância de se consultar um ginecologista, o uso de métodos contraceptivos, as doenças sexualmente transmissíveis e a gravidez na adolescência. No que diz respeito à gravidez na adolescência, foram debatidos temas como aborto, realização de consultas pré-natais, motivos que levam uma adolescente à gravidez e expectativas em torno da gestação. Também foram realizadas reflexões acerca do significado de se ter um filho e sobre os significados atribuídos pelas meninas à maternidade. Neste trabalho, será enfocada somente a questão da gravidez na adolescência, a qual se fez presente de forma significativa durante os encontros.

A gravidez na adolescência constitui-se em um fenômeno complexo, que ainda levanta vários questionamentos. Alguns autores a con- 
sideram um problema de saúde pública (Bozon \& Heilborn, 2006; L. Silva \& Tonete, 2006; Trindade \& Menandro, 2002). Outros acreditam que esse enfoque da gravidez na adolescência como um problema pode provocar lacunas no entendimento da temática, mostrando-se insuficiente para explicar a complexidade do fenômeno (Dadoorian, 2003; Moreira, 2003; Uziel \& Santana, 2008). Ao se analisar a gravidez na adolescência unicamente como um problema, desenvolvem-se barreiras relacionadas tanto à possibilidade de reflexão teórica, quanto às intervenções que podem ser realizadas com adolescentes por meio de projetos de saúde e de educação (Moreira, 2003).

A experiência de trabalho junto às adolescentes evidenciou essa realidade. Duas das meninas participantes das oficinas, Vanessa e Roberta, ambas de quinze anos, afirmaram estar grávidas. No entanto, alguns meses após, soube-se que Roberta não estava grávida e que ela havia deixado de frequentar a escola por motivos desconhecidos pela equipe e instituição. Vanessa, por sua vez, abandonou a escola devido à gravidez.

Destaca-se que todas as meninas participantes das oficinas afirmavam ter conhecimento dos métodos contraceptivos. Roberta, que afirmou estar grávida, em dado momento mostrou ao grupo os preservativos que sempre carregava consigo no bolso da calça ou dentro da bolsa. No entanto, revelou que nem sempre os usava quando mantinha relações sexuais. Nesse sentido, muitos pesquisadores constataram que a maioria das adolescentes que engravidam, têm informações e conhecimento sobre os métodos contraceptivos. Assim, às vezes as adolescentes têm conhecimento dos riscos e das formas de evitar a gravidez, mas não põe em prática isso e geralmente não sabem explicar o que as leva a agir dessa maneira (Tavares, 1996).

Assim, as causas da gravidez na adolescência não se relacionam exclusivamente à desinformação sobre questões sexuais, mas também podem estar ligadas ao desejo da adolescente de ter um filho a fim de testar sua feminilidade a partir da comprovação de seu potencial reprodutivo, ou ainda pode estar relacionada apenas ao desejo de ter um filho (Dadoorian, 2003). Em uma das oficinas, Vanessa (15 anos) falou ao grupo sobre sua gravidez. Ao ser questionada se aquela gravidez havia sido planejada, ela respondeu afirmativamente, dizendo que ela e o namorado haviam conversado e decidido ter um filho.

Salienta-se que, para muitas adolescentes de grupos populares, a maternidade pode tornar-se o papel social mais importante por elas desempenhado. Considerando-se as precárias condições de vida da juventude pobre brasileira, a relação com a maternidade poderia ser considerada uma ruptura com esse destino, já que esta poderia lhes conferir um reconhecimento social (Uziel \& Santana, 2008). A maternidade é um fenômeno valorizado socialmente, sendo considerado por muitas mulheres um evento fundamental em suas vidas. Mas, para algumas adolescentes de grupos populares, este sentimento parece estar ainda mais presente, pois, perante a carência de oportunidades sociais que lhes permitam traçar e alcançar outros planos para suas vidas e a ausência de perspectivas para o futuro, a gravidez/maternidade se torna o seu projeto de vida (Castro \& Correa, 2005b; Dadoorian, 2003; A. Santos \& Carvalho, 2006). Salienta-se, no entanto, que a opção pela maternidade não tem necessariamente relação com o desejo de ser mãe ou com o projeto de vida (Uziel \& Santana, 2008). Assim, por tratar-se de um fenômeno complexo, conforme apontado anteriormente, a gravidez na adolescência pode ser analisada e problematizada a partir de inúmeros enfoques.

Estudos têm apontado a mãe como a principal figura de referência nas famílias de grupos populares, sendo vista muitas vezes como aquela que cuida, protege e se preocupa, além de assumir um forte poder de decisão no que se refere ao lar e à educação dos filhos. É comum a mãe ser aquela a quem os filhos recorrem e para junto da qual retornam nos momentos difíceis. Estas atribuições que lhe são conferidas e o lugar que esta mãe vem ocupando parecem contribuir para $o$ desenvolvimento de um sentido de pertencimento e valorização social (Castro \& Correa, 2005b; Sarti, 2004). Uziel e Santana (2008), a partir de um estudo que discute as relações entre maternidade e adolescência em um contexto específico 
de acolhimento institucional, afirmam que a gravidez e a maternidade parecem ser alternativas na vida de adolescentes de grupos populares. Assim, este evento poderia representar para a menina uma maneira de ganhar visibilidade, adquirindo o status de mãe e de mulher, lugares estes socialmente mais reconhecidos. Neste sentido, a constituição da identidade feminina parece estar socialmente vinculada à aquisição do papel de mãe e de cuidadora.

A adolescente Bia (12 anos), que morava com a mãe e os irmãos, relatava com frequência sua reponsabilidade pelas tarefas domésticas e pelo cuidado do irmão mais novo. Ao falar sobre sua rotina após retornar da escola, relatava que a mãe passava a maior parte do dia fora de casa, em função do trabalho, e que durante o dia ela se ocupava com o preparo da comida e a arrumação da casa e, somente após estas tarefas, fazia seus deveres escolares e saia para encontrar as amigas. Em relação a estes aspectos, Castro e Correa (2005b), a partir de pesquisa realizada com jovens pobres, mostram que elas aos poucos vão adotando um estilo de vida ligado ao esforço doméstico, investindo no cuidado do outro e do lar, deixando em segundo plano os estudos e sua vida pessoal. Esta postura parece ser uma reprodução do modo de vida de suas próprias mães, decorrente de sua identificação com as mesmas. "As jovens assumem o papel de dona-de-casa, e pouco a pouco estão na posição de mães” (p. 42). Ao tornarem-se mães, elas passam a assumir responsabilidades e a ter certa autoridade perante seus filhos e diante do lar em que vivem, assim como suas próprias mães.

Com base nestas considerações, colocam-se os seguintes questionamentos: Pensando na centralidade que a figura materna ocupa nestes grupos, na valorização social da maternidade, na chefia assumida e no poder de decisão adquirido pela mãe, poderia despertar na adolescente o desejo de assumir essa posição materna, de constituir sua própria família o mais cedo possível? Seria esta uma busca pela garantia de um "lugar", de um status social, ou pela aquisição de um sentimento de pertencimento, os quais a adolescente não conseguiria encontrar de outras formas?
Kehl (2004) afirma que a gravidez não é o único desafio a ser encarado pelas adolescentes. Na percepção da autora, o mais desafiador é conseguir desenvolver-se e elaborar projetos de vida em uma sociedade onde são prezados a competitividade ilimitada e os valores individualistas. Do mesmo modo,

o mais difícil não é que uma adolescente tenha um filho aos 15 anos, forçando-se a uma generosidade e a uma maturidade no mínimo mais interessante do que a obrigação de divertir-se que persegue sua vida. O difícil é não ser capaz de imaginar outros destinos para a própria liberdade. (Kehl, 2004, p. 111)

Dessa forma, faz-se necessário pensar em ações que possibilitem que esses adolescentes possam construir outros projetos de vida.

\section{A Construção de um Projeto de Vida: Buscando Novos Caminhos}

Velho (2003) cita Schutz (1979) ao referir-se ao conceito de projeto, o qual é definido pela conduta organizada a fim de que determinadas metas sejam alcançadas. $\mathrm{O}$ conceito de campo de possibilidades caminha junto com a noção de projeto, já que designa o espaço a partir do qual é possível formular e implementar projetos. Velho (2004) destaca que não há um projeto individual "puro", nem exclusivamente interno e subjetivo, ou seja, ele sempre existe relacionado ao outro ou ao social. Desse modo, "os projetos são elaborados e construídos em função de experiências socioculturais, de um código, de vivências e interações interpretadas" (p. 26), e são determinados pela história e pelos paradigmas culturais existentes. Salienta-se que um projeto pode sofrer mudanças, ou ainda que um seja substituído por outro. Esta dinamicidade pode ser explicada ao considerar-se que as pessoas possuem uma história de vida e a todo o momento sofrem influências do outro e das transformações históricas.

Neste sentido, as possibilidades singulares, mesmo que relacionadas às disposições internas, estão sujeitas às determinações das relações sociais e à disponibilidade de recursos simbólicos e materiais, os quais se distribuem de forma dife- 
renciada conforme fatores como a idade, a classe social, dentre outros. Desse modo, o trabalho psíquico de construção individualizada de si se dá simultaneamente à reconfiguração do coletivo. (Castro \& Correa, 2005a)

Na sociedade pós-moderna, a "construção de si" se constitui em um desafio para o adolescente/jovem, o qual muitas vezes é levado a trilhar de forma solitária o caminho em busca da definição de valores e condutas e a avaliar de forma individualizada as implicações de suas escolhas (Castro \& Correa, 2005a). Desse modo, a sociedade atual, governada pelo imperativo da mudança, traz consigo o desafio para o jovem construir um projeto de vida, apesar do apagamento das referências.

Pais (2012) observa uma forte orientação dos jovens ao presente, já que o futuro muitas vezes fracassa em proporcionar possibilidades de concretização de suas aspirações. Nestes casos, pode tornar-se difícil a elaboração de projetos de futuro. De forma semelhante, Leccardi (2005) afirma que, perante a imprevisibilidade dos dias atuais, parece haver um esgotamento da própria ideia de projeto. Desse modo, uma trajetória linear, que possa garantir uma trajetória previsível para o acesso à vida adulta, parece se constituir em uma exceção na vida do jovem, nos dias atuais. O ponto de chegada deste percurso é incerto, assim como os trajetos para alcançá-la.

Nesse sentido, pode-se pensar como este cenário reverbera principalmente na vida dos adolescentes de camadas pobres, em especial os que se encontram em situação de vulnerabilidade social, os quais lidam com a incerteza diariamente, incerteza não apenas em relação ao futuro, mas ao presente, $\mathrm{e}$ às necessidades imediatas do dia-a-dia. Será que é possível afirmar a existência de projetos de vida nestes casos?

Apesar das meninas viverem situações de risco e vulnerabilidade, estas encontram momentos para sonhar, fazerem planos e traçar estratégias para realizá-los. Uma das aspirações das adolescentes é ter uma profissão, na maioria das vezes, profissões relacionadas à história de vida delas, como "advogada" e "brigadiana". Mas todas têm o desejo de "ajudar" as pessoas, em especial os familiares, e para isso o estudo é apontado como uma estratégia, como pode ser visto no relato "Eu quero ajudar as pessoas. Eu quero ter um trabalho, estudar, fazer faculdade e um projeto tipo de dança e pedicure. É, eu penso assim" (Bia, 12 anos). Apesar de relatarem sonhos e desejos em relação ao futuro, estes não pareciam vir acompanhados de uma referência concreta e planejada de como poderiam ser alcançados. Por exemplo, em uma das oficinas emergiu entre as meninas a questão do acesso à universidade. Elas afirmaram não ter conhecimento sobre a forma de ingresso a cursos superiores e técnicos e sobre quais instituições poderiam oferecer cursos profissionalizantes. Assim, se considerarmos o conceito de projeto cunhado por Velho, que designa uma conduta organizada a fim de que determinadas metas sejam alcançadas, pode-se pensar que talvez estas adolescentes não possuíssem um projeto profissional definido.

Através dos relatos das adolescentes, pode-se identificar pouca inclusão em atividades sociais, sendo a escola muitas vezes a única oportunidade de inserção na sociedade (Arpini, 2003). Considerando a noção de campo de possibilidades apontada por Velho (2003), destaca-se aqui o conceito de "pertencimento", o qual diz respeito ao encontro do adolescente com redes de apoio social, as quais oferecem proteção e oportunidades, reconhecendo e ativando nele os seus potenciais e apontando para novas perspectivas. "O pertencimento gera vínculos e estabelece projetos de vida e o conhecimento de novas possibilidades de expressão, muitas vezes iniciadas pela aquisição de novos conhecimentos e saberes" (J. E. F. Santos \& Bastos, 2005, p. 261). De maneira geral, o pertencimento pode dar-se a partir do contato significativo do adolescente com pessoas reconhecidas socialmente, que possuem saberes específicos, como uma prática profissional, atividade cultural ou liderança comunitária. As formas de pertencimento podem se dar a partir da inclusão e participação do adolescente em projetos sociais, ONG's, atividades culturais, espaços de profissionalização, dentre outros (J. E. F. Santos \& Bastos, 2005).

Os projetos sociais podem ser espaços que oportunizem ao adolescente realizar encontros significativos, o que pode tornar possível a visu- 
alização de suas potencialidades e a descoberta de possibilidades e, assim, a construção de projetos futuros (J. E. F. Santos \& Bastos, 2005). A escola aberta pode ser entendida como uma forma de pertencimento para as adolescentes. No entanto, identificou-se a necessidade de se refletir visando oportunizar que estas meninas visualizem outras formas de pertencimento, para além da escola, já que esta se constitui em um lugar transitório na vida das mesmas.

Dessa forma, através de uma parceria entre a equipe do projeto de extensão e projetos sociais do município pôde-se oportunizar aos alunos do turno da manhã uma "tarde cultural" com apresentações de projetos sociais (dança e percussão) desenvolvidos no munícipio e ofertados a crianças e adolescentes também pertencentes a contextos marcados por situações de risco. Este momento teve como intuito oferecer aos alunos um momento cultural, oportunizando o conhecimento de projetos sociais, bem como, a possível inserção dos alunos nos projetos do município.

Outra atividade desenvolvida, por meio de uma parceria entre a TV da universidade a qual a equipe de extensão estava vinculada e o projeto de extensão, foi a elaboração e execução de um documentário. Este tratou da infância e adolescência de jovens que frequentavam a Escola Aberta, focando a história dos personagens a partir de sua própria narrativa e usando o contexto escolar como cenário. Os adolescentes que integraram a proposta falaram como transcorreu sua infância e como eles vêm vivendo sua adolescência, assim como quais são seus planos para o futuro. O que justificou a importância de tornar esse tema um produto audiovisual foi o entendimento acerca da importância e da necessidade de desmistificar a vida desses adolescentes e de tantos outros adolescentes que compartilham esta realidade. Ressalta-se que, através destas atividades realizadas nas oficinas, pôde-se proporcionar às meninas a reflexão sobre outros projetos, outros caminhos para se buscar e construir nesta fase do desenvolvimento.

As oficinas foram encerradas com a realização de uma confraternização entre os participantes e a equipe do projeto e uma reunião com a equipe da escola. $\mathrm{O}$ projeto foi retomado no ano seguinte, com o objetivo de desenvolver um plano individual para cada aluno da oficina, pois, a partir da realização das oficinas, notou-se a angústia pela qual passam os alunos da quarta etapa, diante da possível saída da escola. Nesse sentido, é de extrema importância pensar em possibilidades, perspectivas de futuro, traçando um plano individual para cada aluno concluinte. Neste plano individual irá constar o que o adolescente gosta de fazer, suas habilidades e seus desejos. Além disso, possíveis lugares onde poderia ser inserido, como cursos técnicos e profissionalizantes. Esta proposta foi apresentada à escola, no intuito de que a equipe possa desenvolver esta atividade em conjunto com professores, funcionários e direção da escola.

\section{Considerações Finais}

As meninas que participaram das oficinas realizadas na escola aberta tiveram sua infância e adolescência marcada por situações de violência, rejeição, medos e humilhações. De maneira geral, foram privadas de proteção familiar e apresentavam dificuldades de inserção social e elaboração de projetos futuros.

Dessa forma, torna-se necessário pensar em iniciativas que representem ações estratégicas que possam alterar essas situações. Entre as ações, encontram-se os projetos de extensão, que tem o intuito de aproximar a universidade da comunidade, por meio de uma prática voltada para o enfrentamento dos problemas sociais. As oficinas se constituíram em um espaço de diálogo, elaboração de algumas vivências, possibilitando a reflexão sobre projetos de vida. O envolvimento das adolescentes com a proposta, sua participação ativa nas oficinas e a abertura para trazer temas importantes vivenciados em seu cotidiano foram identificados nos encontros.

Além disso, houve uma boa vinculação entre as participantes das oficinas e coordenadoras das mesmas. Mesmo com aquelas que ao longo do ano foram se afastando, por motivos que refletem justamente a realidade em que se encontram, marcada por muita instabilidade (gravidez, 
mudanças de endereço, escola, entre outros), pôde-se identificar uma boa receptividade e um bom relacionamento com o projeto e sua equipe. Destaca-se ainda a importância dada pela equipe à compreensão do contexto, de forma a dar um sentido a cada ausência, garantindo sempre o lugar e a dedicação a cada participante em todos os momentos, trabalhando com o grupo as saídas, afastamentos e mudanças que foram acontecendo. A receptividade e vinculação das participantes podem indicar que foi se estabelecendo uma relação de confiança entre as adolescentes e as coordenadoras, as quais procuraram fazer com que as mesmas se sentissem seguras o suficiente para compartilhar assuntos particulares, íntimos e importantes, sem se sentirem julgadas por isso.

Certamente, esta experiência se reveste de um significado muito especial para as autoras, por ter buscado ir além das aparentes descrições iniciais do grupo, as quais frequentemente se apresentam muito desqualificadas. Assim, ao mergulhar em suas histórias singulares, encontramos afeto e sofrimento, sonhos e desejos muitas vezes pouco encorajados a se manifestar por serem engolidos por uma realidade onde muitos não passam de um número negativo a contar nas estatísticas.

Ao indagar sobre o que esta experiência pode ter de inovadora, um dos aspectos mais relevantes a destacar é a possibilidade vivenciada por cada adolescente de ser escutada em sua singularidade, ter encontrado alguém aberto a escutar suas dores, temores e sonhos, pois, com muita frequência, as referências a esse grupo social tendem a falar deles no plural, colocando-os todos como uma unidade coletiva. Esse aspecto parece importante porque só será possível produzir mudanças efetivas quando se oferecer a cada adolescente a possibilidade de ser nomeado e reconhecido com sujeito singular, que carrega uma histórica única e que precisa fazer sentido. Quem poderia abrir mão dessa experiência singular de sentir-se alguém na relação com o outro, de despertar o interesse do outro de modo a poder compartilhar sentidos de vida? Talvez esta seja uma das mais importantes ferramentas de que dispomos para alterar a realidade posta.
Considera-se ainda, que o atendimento ofertado à criança e ao adolescente em situação de vulnerabilidade social deve ser realizado de maneira integrada e articulada com a rede de proteção da criança e do adolescente como previsto no Estatuto da Criança e do Adolescente (Lei ${ }^{\circ}$ $8.069,1990)$. Neste sentido, faz-se necessário o envolvimento de diferentes profissionais e diversas instituições para dar conta das questões que envolvam os meninas e meninos inseridos nestas oficinas.

\section{Referências}

Ariès, P. (1981). História social da criança e da família. Rio de Janeiro, RJ: Guanabara.

Arpini, D. M. (2003). Violência e exclusão: Adolescência em grupos populares. Bauru, SP: Editora da Universidade Sagrado Coração.

Arpini, D. M., \& Quintana, A. M. (2009). Família e instituições de abrigo: Reconstruindo relações. In D. M. Arpini (Ed.), Psicologia, família e instituição (pp. 9-28). Santa Maria, RS: Editora da Universidade Federal de Santa Maria.

Arpini, D. M., Siqueira, A. C., \& Savegnago, S. D. O. (2012). Trauma psíquico e abuso sexual: O olhar de meninas em situação de vulnerabilidade. Psicologia, Teoria e Prática, 14(2), 88-101. Recuperado em http://pepsic.bvsalud.org/pdf/ ptp/v14n2/v14n2a08.pdf

Assis, S. G., Avanci, J. Q., Pesce, R. P., Pies, T. O., \& Gomes, D. L. (2012). Notificações de violência doméstica, sexual e outras violências contra crianças no Brasil. Ciência \& Saúde Coletiva, 17(9), 2305-2317. doi:10.1590/S141381232012000900012

Bozon, M., \& Heilborn, M. L. (2006). Iniciação à sexualidade: Modos de socialização, interações de gênero e trajetórias individuais. In M. L. Heilborn, E. M. L. Aquino, M. Bozon, \& D. R. Knauth (Eds.), O aprendizado da sexualidade: Reprodução e trajetórias sociais de jovens brasileiros (pp. 155-206). Rio de Janeiro, RJ: Garamond.

Castro, L. R., \& Correa, J. (2005a). Juventudes, transformações do contemporâneo e participação social. In L. R. Castro \& J. Correa. (Eds.), Juventude contemporânea: Perspectivas nacionais e internacionais (pp. 9-26). Rio de Janeiro, RJ: NAU. 
Castro, L. R., \& Correa, J. (2005b). Mostrando a real: Um relato da juventude pobre do Rio de Janeiro. Rio de Janeiro, RJ: NAU.

Cecconello, A. M., Antoni, C. D., \& Koller, S. H. (2003). Práticas educativas, estilos parentais e abuso físico no contexto familiar [Número especial]. Psicologia em Estudo, 8, 45-54. doi:10.1590/S1413-73722003000300007

Conselho Estadual dos Direitos da Criança e do Adolescente. (1999). Manual de perguntas e respostas para criação e estruturação dos Conselhos Municipais dos Direitos da Criança e do Adolescente, Conselhos Tutelares e Fundos Municipais. Porto Alegre, RS: Completa.

Conselho Federal de Psicologia. (2009). Serviço de proteção social a crianças e adolescentes vitimas de violência, abuso e exploração sexual e suas famílias: Referências para a atuação do psicólogo. Recuperado em http://crepop.pol. org.br/publique/media/Livro_ServicoProtecao_ GRAFICA.pdf

Dadoorian, D. (2003). Gravidez na adolescência: Um novo olhar. Psicologia: Ciência e Profissão, 23(1), 84-91. doi:10.1590/S141498932003000100012

Eliachef, C. (2007). Todos vítimas? A propósito dos maus-tratos à criança. In S. A. Altoé (Ed.), Lei e as leis: Direito e Psicanálise (pp. 163-172). Rio de Janeiro. RJ: Revinter.

Groeninga, G. C. (2003). Família: Um caleidoscópio de relações. In G. C. Groenginga \& R. C. Pereira (Eds.), Direito de Família e Psicanálise: Rumo a uma nova epistemologia (pp. 125-142). Rio de Janeiro, RJ: Imago.

Habigzang, L. F., Koller, S. H., Azevedo, G. A., \& Machado, P. X. (2005). Abuso sexual infantil e dinâmica familiar: Aspectos observados em processos jurídicos. Psicologia: Teoria e Pesquisa, 21(3), 341-348. doi:10.1590/S010237722005000300011

Ippolito, R. (2004). Guia escolar: Método para identificação de sinais de abuso e exploração sexual de crianças e adolescentes. Brasília, DF: Presidência da República, Secretaria Especial dos Direitos Humanos.

Kehl, M. R. (2003). Em defesa da família tentacular. In G. C. Groeninga \& R. C. Pereira (Eds.), Direito de Família e Psicanálise: Rumo a uma nova epistemologia (pp. 163-176). Rio de Janeiro, RJ: Imago.
Kehl, M. R. (2004). A juventude como sintoma da cultura. In R. Novaes \& P. Vannuchi (Eds.), Juventude e sociedade: Trabalho, educação, cultura e participação (pp. 89-114). São Paulo, SP: Fundação Perseu Abramo.

Kehl, M. R. (2008). A fratria órfã: Conversas sobre a juventude. São Paulo, SP: Olho D’Água.

Leccardi, C. (2005). Por um novo significado do futuro: Mudança social, jovens e tempo. Tempo Social, 17(2), 35-57. doi:10.1590/S010320702005000200003

Lei $\mathrm{n}^{\circ}$ 8.069, de 13 de julho de 1990. (1990, 27 set.). Estatuto da Criança e do Adolescente. Diário Oficial da União.

Meyer, D. E. E., Mello, D. F., Valadão, M. M., \& Ayres, J. R. C. M. (2006). "Você aprende. A gente ensina?" Interrogando relações entre educação e saúde desde a perspectiva da vulnerabilidade. Caderno de Saúde Pública, 22(6), 13351342. doi:10.1590/S0102-311X2006000600022

Moreira, M. I. C. (2003). Laços familiares e laços geracionais: Uma reflexão sobre a gravidez entre mulheres adolescentes. In S. M. G. Souza (Ed.), Infância e adolescência: Múltiplos olhares ( $p p$. 113-143). Goiânia, GO: Editora da Pontificia Universidade Católica de Goiás.

Neder, G. (1994). Ajustando o foco das lentes: Um novo olhar sobre a organização das famílias no Brasil. In S. M. Kaloustian (Ed.), Família brasileira, a base de tudo (pp. 26- 46). São Paulo, SP: Cortez.

Pais, J. M. (2012). A esperança em gerações de futuro sombrio. Estudos Avançados, 26(75), 267-280. doi:10.1590/S0103-40142012000200018

Pereira, C. R. R., \& Arpini, D. M. (2012). Os irmãos nas novas configurações familiares. Psicologia Argumento, 30(69), 275-285. doi:10.7213/psicol.argum.5974

Polli, R. G., \& Arpini, D. M. (2012). O olhar de meninos de grupos populares sobre a família. Estudos de Psicologia (Campinas), 29(4), 531-540. doi:10.1590/S0103-166X2012000400008

Ramos, N. V. (2004). O significado da escola aberta para jovens egressos: Continuum de experiências, um ensinar a ser (Tese de doutorado em Educação, Universidade Federal do Rio Grande do Sul, Porto Alegre, RS, Brasil).

Rizzini, I., Rizzini, I., Naiff, L., \& Baptista, R. (2006). Acolhendo crianças e adolescentes: Ex- 
periências de promoção do direito à convivência familiar e comunitária no Brasil. São Paulo, SP: Cortez.

Santos, A., \& Carvalho, C. V. (2006). Gravidez na adolescência: Um estudo exploratório. Boletim de Psicologia, 54(125), 135-151. Recuperado em http://pepsic.bvsalud.org/pdf/bolpsi/ v56n125/v56n125a02.pdf

Santos, J. E. F., \& Bastos, A. C. S. (2005). Pertencimento e "desterro" nas trajetórias de adolescentes da favela de Novos Alagados, Salvador, Bahia. In L. R. Castro \& J. Correa (Eds.), Juventude contemporânea: Perspectivas nacionais e internacionais (pp. 253-277). Rio de Janeiro, RJ: NAU.

Sarti, C. A. (2004). O jovem na família: O outro necessário. In R. Novaes \& P. Vannuchi (Eds.), Juventude e sociedade: Trabalho, educação, cultura e participação (pp. 115-129). São Paulo, SP: Fundação Perseu Abramo.

Silva, L., \& Tonete, V. L. P. (2006). A gravidez na adolescência sob a perspectiva dos familiares: Compartilhando projetos de vida e cuidado. Revista Latino-Americana de Enfermagem, 14(2), 199. 206. doi:10.1590/S0104-11692006000200008

Silva, M. L., Polli, R. G., Sobrosa, G. M. R., Arpini, D. M., \& Dias, A. C. G. (2012). Da normatização a compreensão: Caminhos construídos para a intervenção familiar. Mudanças, 20(1-2), 12-21. doi:10.15603/2176-1019/mud.v20n1-2p13-21

Soares, L. E. (2004). Juventude e violência no Brasil contemporâneo. In R. Novaes \& P. Vannuchi (Eds.), Juventude e sociedade: Trabalho, educação, cultura e participação (pp. 130-159). São Paulo, SP: Fundação Perseu Abramo.

Tavares, E. (1996). Mãe menininha. In A. I. Corrêa (Ed.), Mais tarde é agora! Ensaios sobre a adolescência (pp. 101-115). Salvador, BA: Álgama.
Trindade, Z. A., \& Menandro, M. C. S. (2002). Pais adolescentes: Vivência e significação. Estudos de Psicologia (Natal), 7(1), 15-23. doi:10.1590/ S1413-294X2002000100003

Uziel, A. P., \& Santana, L. S. (2008). Maternidade, adolescência e abrigamento: Compondo equações possíveis. Polêm!ca, 7(3), 25-38.

Vargas, M. D., Buss, A. M., \& Bayer, F. (2008). Limites no discurso psicanalítico num trabalho com crianças e adolescentes em situação de risco. In Pontifícia Universidade Católica do Paraná (Ed.), Anais do VIII Congresso Nacional de Educação-EDUCERE (pp. 12189-12195). Curitiba, PR: Champagnat. Recuperado em http:// www.pucpr.br/eventos/educere/educere2008/ anais/pdf. /750_732.pdf

Velho, G. (2003). Projeto e metamorfose: Antropologia das Sociedades Complexas (3. ed.). Rio de Janeiro, RJ: Jorge Zahar.

Velho, G. (2004). Individualismo e cultura: Notas para uma Antropologia da Sociedade Contemporânea. Rio de Janeiro, RJ: Jorge Zahar.

Winnicott, D. W. (2005). Tudo começa em casa (P. Sandler, Trad.). São Paulo, SP: Martins Fontes. (Original publicado em 1986)

Yunes, M., A. M., \& Szymanski, H. (2003). Crenças, sentimentos e percepções acerca da noção de resiliência em profissionais da Saúde e Educação que atuam com famílias pobres. Psicologia $d a$ Educação, 17, 119-137.
Recebido: 20/06/2014

$1^{a}$ revisão: 18/09/2014 Aceite final: 26/09/2014 